\title{
Autologous GM-CSF-secreting Lethally Irradiated Colorectal Cancer Cell Vaccine
}

National Cancer Institute

\section{Source}

National Cancer Institute. Autologous GM-CSF-secreting Lethally Irradiated Colorectal

Cancer Cell Vaccine. NCI Thesaurus. Code C111991.

\begin{abstract}
A lethally irradiated, autologous colorectal cancer vaccine consisting of patient-specific colorectal cancer cells genetically modified to secrete the cytokine granulocytemacrophage colony stimulating factor (GM-CSF), with potential immunostimulating and antineoplastic activities. Upon vaccination, the autologous GM-CSF-secreting lethally irradiated colorectal cancer cell vaccine releases GM-CSF. In turn, GM-CSF may increase the body's immune response against tumor cells by promoting the maturation and activation of dendritic cells (DCs), and enhancing tumor-specific antigen presentation to both B- and T-cells, which leads to better recognition of tumors by the immune system. In addition, GM-CSF promotes antibody-dependent cellular cytotoxicity (ADCC), and increases interleukin-2-mediated lymphokine-activated killer cell function.
\end{abstract}

